\title{
Plasmodium falciparum ve Salmonella Typhi Koenfeksiyonu: Bir Olgu Sunumu
}

\section{Plasmodium falciparum and Salmonella Typhi Co-Infection: A Case Report}

\author{
Şua SÜMER ${ }^{1}$, Gaye URAL ${ }^{2}$, Onur URAL ${ }^{1}$ \\ ${ }^{1}$ Selçuk Üniversitesi Tıp Fakültesi, Enfeksiyon Hastalıkları ve Klinik Mikrobiyoloji Anabilim Dalı, Konya. \\ ${ }^{1}$ Selcuk University Faculty of Medicine, Department of Infectious Diseases and Clinical Microbiology, Konya, Turkey. \\ ${ }^{2}$ Konya Numune Hastanesi, Enfeksiyon Hastalıkları ve Klinik Mikrobiyoloji Kliniği, Konya. \\ ${ }^{2}$ Konya Numune Hospital, Infectious Diseases and Clinical Microbiology Clinic, Konya, Turkey.
}

Geliş Tarihi (Received): 19.04.2013 • Kabul Ediliş Tarihi (Accepted): 12.06.2013

\section{ÖZET}

Sıtma ve salmonella enfeksiyonları özellikle gelişmekte olan ülkelerde endemik olarak görülen enfeksiyonlardır. Sıtma ve salmonella koenfeksiyonu ise nadir görülmekle birlikte yüksek mortaliteyle seyredebilir. Koenfeksiyon gelişimindeki temel mekanizma; sıtma sırasında eritrositlerin yıkımı ile ortaya çıkan hemoglobin yapısındaki hem ve hem oksijenaz aracılığıyla granülositlerin mobilizasyonunun bozulması ve bu durumun Salmonella türlerine karşı olan direnci azaltmasıdır. Dolayısıyla sıtmalı bir hasta Salmonella spp. ile karşılaştığında daha kolay enfekte olmaktadır. Bu raporda, Plasmodium falciparum ve Salmonella Typhi koenfeksiyonu olan bir olgunun sunulması amaçlanmıştır. İshal, bulantı, kusma, karın ağrısı, halsizlik ve ateş şikayetleriyle hastaneye başvuran 23 yaşındaki erkek hastanın, yapılan laboratuvar tetkiklerinde trombosit sayısı düşük, ALT, AST ve CRP düzeyleri yüksek bulunmuştur. Hastanın Pakistan'da çalışma öyküsü olması nedeniyle ayırıcı tanıda sıtma düşünülmüş ve yapılan periferik yayma ve kalın damla preparatlarında P.falciparum trofozoitleri görülmüştür. Klorokine dirençli bölgeden geldiği için hastaya sıtma tedavisinde kinin $(3 \times 650 \mathrm{mg})$ ve doksisiklin $(2 \times 100 \mathrm{mg} /$ gün$)$ başlanmıştır. Yatışında ishali olan hastanın dışkı mikroskopisinde eritrosit, parazit yumurtası ve mantar elemanları saptanmamış; dışkı kültüründe patojen mikroorganizma üremesi olmamıştır. Yatışından itibaren ateşli dönemlerinde hastadan alınan kan kültürlerinde bakteri üremesi saptanmış ve izolat S.Typhi olarak tanımlanmıştır. Buna göre P.falciparum ve S.Typhi koenfeksiyonu tanısı konulan hastanın tedavisine antibiyogram sonucuna göre seftriakson (1 x 2 g/gün, 14 gün) eklenmiştir. Uygulanan kombine tedavi (kinin, doksisiklin, seftriakson) ile hastanın ateşi kontrol altına alınmış, genel durumu düzelmiş ve laboratuvar bulguları normale dönmüştür. Ancak sıtma tedavisinin beşinci gününde ani bilateral işitme kaybı gelişmesi üzerine, kinin tedavisi kesilerek artemisinin bazlı kombine tedaviye (artemeter/lumefantrin) geçilmiştir. Artemisinin bazlı tedavide yan etki görülmemiş ve kontrolünde genel durumu iyi olan hastanın işitme kaybı tamamen düzelmiştir. Sonuç 
olarak, sıtmanın endemik olduğu bölgelerden gelen hastalarda sıtma tanısı konulsa da, koenfeksiyon varlığı açısından hasta yakından izlenmeli ve ateşli dönemde yapılan kan kültürleri başta olmak üzere olası tüm enfeksiyonlara yönelik tetkiklerin yapılması gerektiği akılda tutulmalıdır.

Anahtar sözcükler: Plasmodium falciparum; Salmonella Typhi; koenfeksiyon.

\begin{abstract}
Malaria and salmonella infections are endemic especially in developing countries, however malaria and salmonella co-infection is a rare entity with high mortality. The basic mechanism in developing salmonella co-infection is the impaired mobilization of granulocytes through heme and heme oxygenase which are released from haemoglobin due to the breakdown of erythrocytes during malaria infection. Thus, a malaria infected person becomes more susceptible to develop infection with Salmonella spp. In this report a case with Plasmodium falciparum and Salmonella Typhi co-infection was presented. A 23-year-old male patient was admitted to hospital with the complaints of diarrhea, nausea, vomiting, abdominal pain, fatigue and fever. Laboratory findings yielded decreased number of platelets and increased ALT, AST and CRP levels. Since he had a history of working in Pakistan, malaria infection was considered in differential diagnosis, and the diagnosis was confirmed by the detection of P.falciparum trophozoites in the thick and thin blood smears. As he came from a region with chloroquine-resistant Plasmodium, quinine $(3 \times 650 \mathrm{mg})$ and doxycycline $(2 \times 100 \mathrm{mg} /$ day $)$ were started for the treatment. No erythrocytes, parasite eggs or fungal elements were seen at the stool microscopy of the patient who had diarrhoea during admission. No pathogenic microorganism growth was detected in his stool culture. The patient's blood cultures were also taken in febrile periods starting from the time of his hospitalization. A bacterial growth was observed in his blood cultures, and the isolate was identified as $S$. Typhi. Thus, the patient was diagnosed with P.falciparum and Salmonella Typhi coinfection. Ceftriaxone $(1 \times 2 \mathrm{~g} /$ day, 14 days) was added to the therapy according to the results of antibiotic susceptibility test. With the combined therapy (quinine, doxycycline, ceftriaxone) the fever was taken under control, his general condition improved and laboratory findings turned to normal values. However, on the fifth day of his anti-malaria therapy sudden bilateral hearing loss developed due to quinine use. Thus, the treatment was replaced with an artemisinin-based (arthemeter/lumefantrine) combination therapy. No adverse effects were detected due to artemisinin-based therapy, and the patient completely recovered. In conclusion, if a patient is diagnosed with malaria, he/she should be closely monitored in terms of having co-infections and appropriate diagnostic methods including blood cultures taken in febrile episodes should be performed.
\end{abstract}

Key words: Plasmodium falciparum; Salmonella Typhi; co-infection.

\title{
Giriş
}

Sıtma ve salmonelloz, özellikle gelişmekte olan ülkelerde endemik olarak görülen ve fatal komplikasyonların ortaya çıkabildiği ciddi enfeksiyonlardır ${ }^{1,2}$. Sıtma özellikle anemi ve ateşle seyrederken, Salmonella türleri bakteriyemi ataklarına neden olmaktadır. Yapılan çalışmalarda, sıtma enfeksiyonu varlığının salmonella enfeksiyonu gelişimini kolaylaştırdığı; sıtma ve salmonella koenfeksiyonunun mortaliteyi belirgin oranda artırdığı gösterilmiştir ${ }^{1-4}$. Koenfeksiyon gelişimindeki temel mekanizma; sıtma sırasında eritrositlerin yıkımı ile ortaya çıkan hemoglobin yapısındaki hem ve hem oksijenaz aracılığıyla granülositlerin mobilizasyonunun bozulması ve bu durumun Salmonella türlerine karşı olan direnci azaltmasıdır ${ }^{1}$. Bu raporda, endemik bölgeden gelen bir olguda saptanan Plasmodium falciparum ve Salmonella Typhi koenfeksiyonu sunulmaktadır. 


\section{OLGU SUNUMU}

Yirmi üç yaşında erkek hasta 15 gündür süren ishal, bulantı, kusma, karın ağrısı, halsizlik ve ateş şikayetiyle başvurdu. Hastanın anamnezinden 6 aydır Pakistan'da çalıştığı, şüpheli gıda tüketimi ve ilaç kullanım öyküsü olmadığı öğrenildi. Fizik muayenesinde ateşi $37^{\circ} \mathrm{C}$, dil kuru paslı olup, karaciğer ve dalak ele gelmiyordu. Bağırsak sesleri hiperaktif olan hastanın diğer sistem muayeneleri normaldi. Laboratuvar tetkiklerinde trombosit sayısı $115.000 / \mathrm{mm}^{3}\left(150.000-400.000 / \mathrm{mm}^{3}\right)$, AST: $99 \mathrm{U} / \mathrm{L}(8-33 \mathrm{U} / \mathrm{L})$, ALT: $68 \mathrm{U} / \mathrm{L}$ (0-55 U/L) ve CRP: $75 \mathrm{mg} / \mathrm{dl}(0-5 \mathrm{mg} / \mathrm{dl})$ olarak saptandı. Diğer laboratuvar tetkikleri normaldi. Dışkı mikroskobisinde her alanda 3-5 lökosit görüldü. Eritrosit, parazit yumurtası ve mantar elemanları görülmedi. Dışkı kültüründe patojen mikroorganizma üremesi saptanmadı. Sıvı tedavisi planlanan hastanın ateşi düzenli bir ritim göstermeden 37.8$38^{\circ} \mathrm{C}$ arasında seyretti. Sıtmanın endemik olduğu bir bölgeden gelmesi nedeniyle, ateşli dönemde alınan kan örneğinden yapılan kalın damla ve periferik yayma preparatlarında P.falciparum trofozoitleri görüldü (Resim 1). Yatışından itibaren hastanın ateşli dönemlerinde kan kültürleri alındı. Yatışının ikinci gününde sıtma tanısı konulan hastaya, klorokin direncinin olduğu bir bölgeden geldiği için kinin $(3 \times 650 \mathrm{mg})$ ve doksisiklin $(2 \times 100$ mg/gün) tedavisi başlandı. Yatışının üçüncü gününde hastanın ateşli döneminde alınan kan kültürlerinde üreyen bakteri konvansiyonel yöntemlerle S.Typhi olarak tanımlandı. Antibiyotik duyarlılık testinde izolatın seftriaksona duyarlı bulunması nedeniyle hastanın tedavisine seftriakson ( $1 \times 2 \mathrm{~g} /$ gün) eklendi.

P.falciparum ve S.Typhi koenfeksiyonu tanısı konulan hastanın ishal sayısı tedaviyle azaldı ve takibinde ateşi kontrol altına alındı. Genel durumu düzelen ve ateşsiz takip edilen hastanın sıtma tedavisinin beşinci gününde kinine bağlı ani, bilateral \%70 işitme kaybı gelişti. Kinin tedavisi kesilerek artemeter/lumefantrin (artemisinin grubu) ile

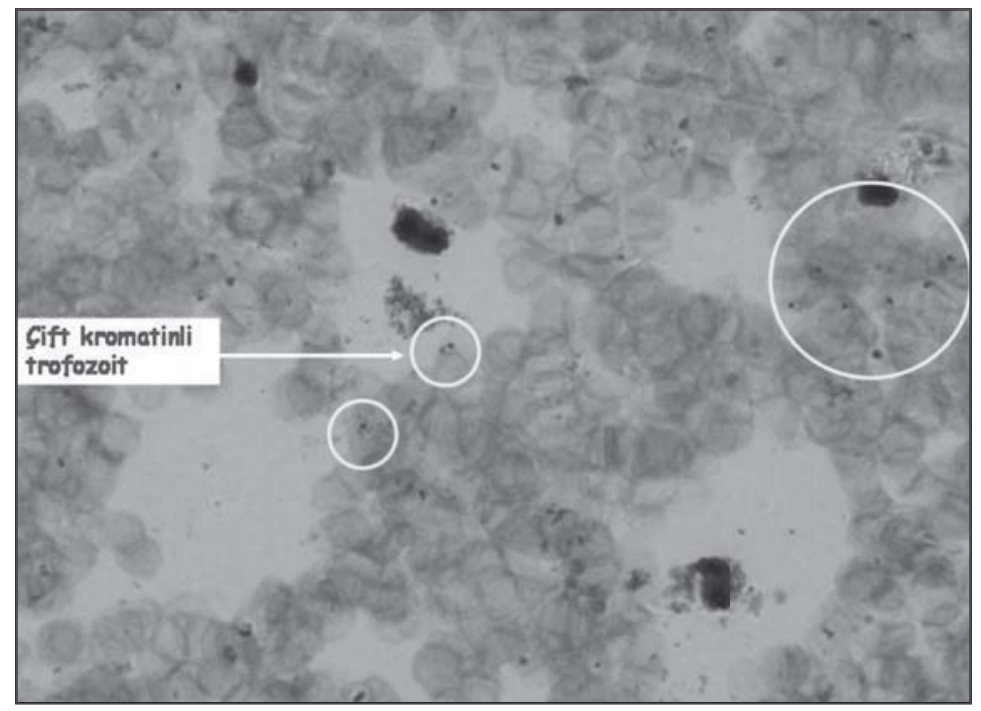

Resim 1. Kalın damla preparatında görülen çok sayıda çift kromatinli P.falciparum trofozoitleri. 
üç günlük tedavi verildi. Seftriakson tedavisi 14 güne tamamlanarak kesildi. Hastanın laboratuvar tetkikleri normale döndü. Şikayetleri düzelen ve ateşi olmayan hasta 10 gün sonra kontrole çağrılarak taburcu edildi. Kontrolünde genel durumu iyi olan hastanın ateşi yoktu ve işitme kaybı tamamen düzeldi.

\section{TARTIŞMA}

Sıtma ve salmonella koenfeksiyonu nadir görülen, ancak mortalitesi yüksek olan enfeksiyonlardandır. Sıtmada etken olan dört plasmodium türünden en ağır kliniğe sahip olan P.falciparum'dur. Salmonella enfeksiyonları ise bakteriyemiden lokalize enfeksiyonlara ve kronik taşıyıcılığa kadar değişebilen klinik özelliklerle karşımıza çıkabilir ${ }^{1-3}$.

Farklı klinik bulgular ile seyredebilen sıtmanın prodromal döneminde halsizlik, iştahsızlık, baş ağrısı, miyalji, artralji, karın ağrısı ve ishal görülebilir. Eğer hastanın, sıtma için endemik bir bölgeye seyahat veya kan transfüzyonu öyküsü varsa, ön tanıda sıtma mutlaka düşünülmelidir. Prodromal dönem sonunda üşüme, titreme, yüksek ateş ve terleme ile karakterize sıtma nöbetleri başlar. Başlangıçta nöbetler düzensiz olabilir; özellikle P.falciparum'da düzenli ateş nöbetleri görülmez. Bu nedenle tipik sıtma nöbetleri görülmeden, sürekli ateşin izlendiği olgularda ayıııcı tanı zorlaşır ${ }^{5,6}$. Bizim olgumuzda başvuru bulguları sıtma için tipik olmamasına rağmen, endemik bölgeye seyahat öyküsünün bulunması nedeniyle ayırıcı tanılar arasında sıtma düşünülerek ince yayma ve kalın damla preparatları hazırlanmıştır. Sıtma tanısında, uygun şekilde boyanmış kan yaymasının ışık mikroskobu ile incelenerek parazitin görülmesi altın standart yöntemdir. P.falciparum trofozoitleri ise çift kromatinli olup "telefon ahizesi" şeklinde görülmekte$\mathrm{dir}^{6,7}$. Olgumuzun tanısı, periferik yayma ve kalın damla preparatlarında P.falciparum trofozoitlerinin görülmesiyle konulmuştur (Resim 1).

Sıtma tedavisi, Plasmodium türüne, hastanın klinik durumuna ve ilaç duyarlıığına göre düzenlenir. Enfeksiyonun kazanıldığı bölgede klorokin direncinin varlığı önemli bir belirleyicidir. Klorokine dirençli P.falciparum enfeksiyonları kinin, doksisiklin, atovakuon/proguanil, meflokin veya artemisinin bazlı kombine ilaçlarla tedavi edilebilir. Antimalaryal ilaçlar içinde en eskisi olan kinin gastrointestinal rahatsızlık, görme ve işitme bozukluklarına neden olabilir. İşitme ve görme kaybı genellikle geri döner; körlük nadiren ortaya çıkar ${ }^{8}$. Yan etki varlığında tedavi değişikliği önerilmektedir. Bizim olgumuza başlangıçta kinin ve doksisiklinden oluşan kombinasyon tedavisi başlanmış, ancak tedavinin beşinci gününde işitme kaybı gelişmesi üzerine tedavi artemisinin bazlı kombine ilaçla değiştirilmiştir. Tedavinin değiştirilmesinden sonra hastanın işitme kaybı düzelmiştir.

Salmonella türleri, özellikle immün süpresif bireylerde, vasküler hastalığı olanlarda ve başta orak hücreli anemi olmak üzere diğer kan hastalıkları olan kişilerde daha kolay enfeksiyon oluşturmaktadır ${ }^{9,10}$. Bakteriyemisi olan hastalarda, uygun zamanda ve uygun şekilde alınan kan kültürlerinde Salmonella türleri enfeksiyonun birinci haftasından sonra saptanabilir $^{10}$. S.Typhi enfeksiyonunun klinik seyrinde ateş, rölatif bradikardi, roseoller, dikrot nabız ve ishal gibi pek çok bulguya rastlanılabilir ${ }^{9,10}$. Bizim olgumuzda ateş ve ishal olmakla birlikte tifoda görülen tipik bulgular tespit edilememiş; yine de ateşli dönemlerde kan kültürü alınmasıyla bu koenfeksiyonun gözden kaçırılması önlenmiştir. 
Kan kültüründe üreyen bakteri S.Typhi olarak tanımlanmış ve antibiyogram sonucunda elde edilen duyarlılık profiline göre hastaya uygun tedavi verilmiştir. Salmonella türleri genel olarak seftriakson ve siprofloksasin başta olmak üzere birçok antibiyotiğe duyarlıdır ${ }^{9}$. Olgumuzda da 14 günlük seftriakson tedavisi ile tam iyileşme sağlanmıştır.

Sonuç olarak, sıtmanın endemik olduğu bölgelerden gelen hastalarda eşlik edebilecek diğer koenfeksiyonların olabileceği ve koenfeksiyon varlığının mortaliteyi artırabileceği unutulmamalıdır.

\section{KAYNAKLAR}

1. Cunnington AJ, de Souza JB, Walther M, Riley EM. Malaria impairs resistance to Salmonella through hemeand heme oxygenase-dependent dysfunctional granulocyte mobilization. Nat Med 2011; 18(1): 120-7.

2. Berkley JA, Bejon P, Mwangi T, et al. HIV infection, malnutrition, and invasive bacterial infection among children with severe malaria. Clin Infect Dis 2009; 49(3): 336-43.

3. Mabey DC, Brown A, Greenwood BM. Plasmodium falciparum malaria and Salmonella infections in Gambian children. J Infect Dis 1987; 155(6): 1319-21.

4. Bronzan RN, Taylor TE, Mwenechanya J, et al. Bacteremia in Malawian children with severe malaria: prevalence, etiology, HIV coinfection, and outcome. J Infect Dis 2007; 195(6): 895-904.

5. Ural O. Sıtma kliniği. Turkiye Klinikleri J Inf Dis-Special Topics 2012; 5(2): 15-9.

6. Özcel MA (ed). Sıtma. 1999, 1.Baskı. Ege Üniversitesi Basımevi, İzmir.

7. Sümer Ş. Sıtma tanısı. Turkiye Klinikleri J Inf Dis-Special Topics 2012; 5(2): 20-9.

8. Dikici N. Sitma tedavisi. Turkiye Klinikleri J Inf Dis-Special Topics 2012; 5(2): 30-44.

9. Willke Topçu A, Özbakkaloğlu B. Tifo, s: 909-21. Willke Topçu A, Söyletir G, Doğanay M (ed), İnfeksiyon Hastalıkları ve Mikrobiyolojisi. 2008, 3. Baskı. Nobel Tıp Kitapevleri, İstanbul.

10. Castonguay-Vanier J, Davong V, Bouthasavong L, et al. Evaluation of a simple blood culture amplification and antigen detection method for diagnosis of Salmonella enterica serovar typhi bacteremia. J Clin Microbiol 2013; 51(1): 142-8. 